\title{
Decision-making deficits in patients with chronic schizophrenia: lowa Gambling Task and Prospect Valence Learning model
}

This article was published in the following Dove Press journal:

Neuropsychiatric Disease and Treatment

22 April 2016

Number of times this article has been viewed

\section{Myung-Sun Kim' \\ Bit-Na Kang' \\ Jae Young Lim²}

'Department of Psychology, Sungshin Women's University, Seoul, Republic of Korea; ${ }^{2}$ Department of Psychiatry, Keyo Medical Foundation, Keyo Hospital, Uiwang, Republic of Korea
Correspondence: Myung-Sun Kim Department of Psychology, Sungshin Women's University, Dongsun 3ga, Sungbuk, Seoul, Republic of Korea Tel +82 29207592

Fax +82 29202040

Email kimms@sungshin.ac.kr
Purpose: Decision-making is the process of forming preferences for possible options, selecting and executing actions, and evaluating the outcome. This study used the Iowa Gambling Task (IGT) and the Prospect Valence Learning (PVL) model to investigate deficits in risk-reward related decision-making in patients with chronic schizophrenia, and to identify decision-making processes that contribute to poor IGT performance in these patients.

Materials and methods: Thirty-nine patients with schizophrenia and 31 healthy controls participated. Decision-making was measured by total net score, block net scores, and the total number of cards selected from each deck of the IGT. PVL parameters were estimated with the Markov chain Monte Carlo sampling scheme in OpenBugs and BRugs, its interface to $R$, and the estimated parameters were analyzed with the Mann-Whitney $U$-test.

Results: The schizophrenia group received significantly lower total net scores compared to the control group. In terms of block net scores, an interaction effect of group $\times$ block was observed. The block net scores of the schizophrenia group did not differ across the five blocks, whereas those of the control group increased as the blocks progressed. The schizophrenia group obtained significantly lower block net scores in the fourth and fifth blocks of the IGT and selected cards from deck D (advantageous) less frequently than the control group. Additionally, the schizophrenia group had significantly lower values on the utility-shape, loss-aversion, recency, and consistency parameters of the PVL model.

Conclusion: These results indicate that patients with schizophrenia experience deficits in decision-making, possibly due to failure in learning the expected value of each deck, and incorporating outcome experiences of previous trials into expectancies about options in the present trial.

Keywords: IGT, PVL model, risk-reward related decision-making

\section{Introduction}

Decision-making is the process of forming preferences for possible options, selecting and executing actions, and evaluating the outcome. ${ }^{1,2}$ Recently, decision-making in patients with schizophrenia has received attention, as functional disabilities, including impairments in motivation and pursuit of long-term goals in patients with this disorder are associated with deficits in decision-making. ${ }^{3}$

The Iowa Gambling Task (IGT) is widely used to measure decision-making ability, as this task simulates real-life decision-making by manipulating the possibilities and magnitudes of potential rewards and punishments. ${ }^{4}$ Specifically, the IGT is sensitive to risk-reward related decision-making because participants have to learn to sacrifice immediate rewards in favor of long-term benefits, and performance on the IGT is 
strongly influenced by emotional factors related to rewards and penalties. ${ }^{5}$ On each trial of the IGT, the participant selects a card from one of four decks; each selection of a card leads to a gain, which is sometimes coupled with a simultaneous loss. Two decks (A and B) are disadvantageous, and selecting cards from these decks results in an overall net loss; however, the other two decks (C and D) are advantageous, and selecting cards from these decks results in an overall net gain. The participant is instructed to maximize the net payoff across trials without being informed of which decks are advantageous or disadvantageous. In other words, the IGT requires that the participant learn the expected value of each deck associated with the response choice while performing the task. ${ }^{6}$ Decision-making is measured by the total net score, the block net scores, and the total number of cards selected from each deck. ${ }^{7}$ The total net score is calculated as the total number of cards selected from advantageous decks minus the total number of cards selected from disadvantageous decks. The 100 total trials are divided into five blocks, and block net scores are calculated in the same way as the total net score. The total net score provides information about the participant's general decision-making ability, and the block net scores provide a learning curve that reflects whether the participant learned the contingency governing gain and loss between the first and fifth block. ${ }^{7}$ Healthy participants choose cards from advantageous decks more than from the disadvantageous decks as the task progresses from the first to the fifth block. ${ }^{8-11}$

Studies using the IGT to investigate decision-making in patients with schizophrenia have produced inconsistent results. Some have reported that patients with schizophrenia chose cards from disadvantageous decks more than healthy controls did, ${ }^{10-12}$ and that the block net scores of the patient group did not increase as the test progressed. ${ }^{9,13-15}$ For example, Lee et al ${ }^{13}$ observed that patients with schizophrenia were more likely to select cards from deck B and less likely to select cards from deck D, compared with healthy control participants and that they had significantly lower block net scores in the fourth and fifth blocks than healthy controls. However, two studies have reported relatively intact IGT performance in patients with schizophrenia compared with healthy controls. ${ }^{16,17}$ Inconsistent findings across studies may be explained by differences in the clinical features of the patients with schizophrenia who participated in the different studies. For example, Beninger et $\mathrm{al}^{18}$ reported that patients receiving atypical, but not typical, antipsychotic drugs performed worse on the gambling task than normal controls. Additionally, Shurman et a ${ }^{10}$ observed that patients with more negative symptoms performed worse on the IGT, and Struglia et $\mathrm{al}^{11}$ reported that positive symptoms were associated with poor performance on the IGT.

Although the IGT is a sensitive measure of risk-reward related decision-making under conditions of complexity and uncertainty, the total net and block net scores do not provide information about the specific decision-making processes that contribute to performance. ${ }^{8}$ Several mathematical models have been developed to identify the mechanisms underlying the decision-making processes involved in the IGT. For example, Busemeyer and Stout ${ }^{19}$ proposed the Expectancy Valence Learning (EVL) model to disentangle the processes contributing to IGT performance and to identify the processes that contribute to poor IGT performance. The EVL model assumes that three parameters, namely attention to winning, recency, and consistency, determine IGT performance. The attention-to-winning parameter assesses the participants' tendency to attend to winning more than to losing. The recency parameter addresses how the expectancies for each deck are updated based on recent experiences of a particular outcome. The consistency parameter reflects the degree of consistency between deck selections and the expected outcomes associated with each deck. ${ }^{19,20}$

Recently, Ahn et $\mathrm{al}^{21}$ developed the Prospect Valence Learning (PVL) model based on the EVL model, which assumes four parameters: utility shape, loss aversion, recency, and consistency. Utility shape and loss aversion are associated with subjective evaluations about the outcomes of choices. The utility-shape parameter determines the shape of the utility function, which is a subjective judgment about the likelihood of certain outcomes, and the loss-aversion parameter evaluates the tendency to avoid loss. The recency parameter measures the formation or modification of preferences for each deck based on recent experiences with a particular outcome, and the consistency parameter reflects the consistency of choice behavior. Based on the results of a study that compared the two decision learning models, Ahn et $\mathrm{al}^{21}$ suggested that the PVL model is better than the EVL model in explaining the mechanisms underlying decision-making. For example, because the PVL model uses a nonlinear utility function instead of the linear function used by the EVL model, the PVL model can account for the gain-loss frequency effect on the formation of expectancy for each deck, which the EVL model cannot explain. ${ }^{21}$ In addition, the authors suggest that the PVL model is better at making predictions for the very next trial based on recent experiences (ie, short-term prediction) and in predicting more complex choice behavior such as choosing one among four 
alternatives, as IGT participants are required to do. On the other hand, the EVL model is better than the PVL model in making predictions for the entire sequence of choices (ie, long-term prediction), and in predicting simple choice behavior such as choosing one of two alternatives. A study comparing the EVL and PVL models in substance abusers demonstrated that the PVL model explained the observed data better than the EVL model..$^{22}$

A few studies have used the EVL model to investigate performance on the IGT in patients with schizophrenia. For example, Kester et $\mathrm{al}^{9}$ reported that patients with schizophrenia devoted more attention to gains than healthy control participants, and Premkumar et $\mathrm{al}^{15}$ and Brambilla et $\mathrm{al}^{23}$ observed that patients with schizophrenia were less likely to incorporate previous experience into current choices than healthy controls. In addition, patients with schizophrenia showed less consistency in their choices compared with healthy controls. ${ }^{23}$ To our knowledge, no research has used the PVL model to investigate the performance of patients with schizophrenia on the IGT.

We investigated risk-reward related decision-making in patients with schizophrenia using the IGT and the PVL model. The primary objectives of the study were to investigate whether patients with chronic schizophrenia showed deficits in decision-making and, if so, to identify the specific decision-making processes that contribute to poor IGT performance in these patients.

\section{Materials and methods Participants}

Thirty-nine right-handed patients with schizophrenia (18 males and 21 females) were selected from the patient population participating in the Social Return Program, which is administered by local psychiatric hospitals. This program focuses on improving social adaptation in patients, and there are no special requirements for participation in this program.
Schizophrenia was diagnosed by psychiatrists based on a clinical interview using the criteria for schizophrenia of the Diagnostic and Statistical Manual for Mental Disorders 4th edition (DSM-IV). ${ }^{24}$ Patients with a history of neurological disorders, head injury, or drug/alcohol abuse were excluded. The severity of schizophrenia symptoms was evaluated using the Positive and Negative Syndrome Scale. ${ }^{25}$ Of the 39 patients, 30 had paranoid-type and nine had undifferentiated-type schizophrenia. The mean illness duration was 16.26 (standard deviation $=4.36$ ) years. All patients received neuroleptic medication at the time of testing. Information regarding antipsychotic drugs and chlorpromazine equivalent $\operatorname{doses}^{26}$ in the schizophrenia group is presented in Table 1.

Thirty-one healthy right-handed control participants (14 males and 17 females) matched to the patients in terms of age, sex, and educational level were selected by advertisements. The structured clinical interview for DSM-IV, non-patient edition ${ }^{27}$ was administered to ensure that none of the normal controls had a history of psychiatric, medical or neurological disorders, or drug/alcohol abuse. All participants provided written informed consent after receiving a complete description of the study, and they were paid for their participation. This study was approved by the Sungshin Women's University Institutional Bioethics Review Board (sswuirb2013-002).

\section{IGT}

The computerized $\mathrm{IGT}^{7}$ was administered to measure riskreward related decision-making. In each trial of this task, four decks of cards are presented on a monitor, and participants select a card from any of the four decks and are informed how much they won or lost by choosing that card. When one card is selected, the gain or loss is presented on the monitor. Gains occur whenever cards are selected, but losses occur according to certain ratios, and the decks differ in terms of the magnitudes and frequencies of gains and losses (Table 2).

Table I Antipsychotic drugs and chlorpromazine equivalent doses in schizophrenia group

\begin{tabular}{|c|c|c|c|c|c|c|c|}
\hline \multicolumn{4}{|l|}{ Atypical } & \multicolumn{4}{|l|}{ Typical } \\
\hline Drug & $\mathbf{n}$ & $\begin{array}{l}\text { Median } \\
(\mathrm{mg})\end{array}$ & $\begin{array}{l}\text { Chlorpromazine } \\
\text { equivalent dose }\end{array}$ & Drug & $\mathbf{n}$ & $\begin{array}{l}\text { Median } \\
(\mathrm{mg})\end{array}$ & $\begin{array}{l}\text { Chlorpromazine } \\
\text { equivalent dose }\end{array}$ \\
\hline Amisulpride & 2 & 600 & 516 & Chlorpromazine & 5 & 300 & 300 \\
\hline Aripiprazole & 5 & 20 & 400 & Haloperidol & 8 & 11.5 & 690 \\
\hline Clozapine & I & 600 & 600 & Perphenazine & I & 18 & 360 \\
\hline Olanzapine & 5 & 20 & 600 & Sulpiride & 3 & 800 & 600 \\
\hline Paliperidone & 4 & 8.35 & 556.95 & & & & \\
\hline Quetiapine & II & 600 & 480 & & & & \\
\hline Risperidone & 18 & 6 & 600 & & & & \\
\hline Zotepine & I & 50 & 100 & & & & \\
\hline
\end{tabular}


Table 2 Magnitude and frequency of gain and loss in each deck of IGT

\begin{tabular}{lllll}
\hline IGT & Deck A & Deck B & Deck C & Deck D \\
\hline Mean gain & $+\$ 100$ & $+\$ 100$ & $+\$ 50$ & $+\$ 50$ \\
Mean loss & $-\$ 250$ & $-\$ 1,250$ & $-\$ 50$ & $-\$ 250$ \\
Loss probability & 5 every 10 trials & Once every 10 trials & 5 every 10 trials & Once every 10 trials \\
Expected value & $-\$ 250$ & $-\$ 250$ & $+\$ 250$ & $+\$ 250$ \\
\hline
\end{tabular}

Note: The currency is USD.

Abbreviation: IGT, lowa Gambling Task.

Participants are instructed to gain as much as possible by selecting cards resulting in maximum gains and minimum losses, but they are not told which decks are advantageous or disadvantageous. A total of 120 trials, including 20 practice trials, were administered in this study. Decision-making ability was measured by total net and block net scores. The total net scores were calculated as the total number of cards selected from advantageous decks minus the total number of cards selected from disadvantageous decks $([\mathrm{C}+\mathrm{D}]-[\mathrm{A}+\mathrm{B}])$. Additionally, the 100 trials were divided into five blocks, and block net scores were calculated the same way as total net scores.

\section{PVL model}

The utility-shape and loss-aversion parameters of the PVL model were measured using the following equations:

$$
u(t)= \begin{cases}x(t)^{a} & \text { if } x(t) \geq 0 \\ -\lambda|x(t)|^{a} & \text { if } x(t)<0 .\end{cases}
$$

In earlier equation, $x(t)$ indicates net gains on the $t^{\text {th }}$ trial $(\operatorname{win}(t)-|\operatorname{loss}(t)|)$, and $\operatorname{win}(t)$ and $\operatorname{loss}(t)$ indicate gains and losses on the $t^{\text {th }}$ trial, respectively. The utility-shape parameter $(\alpha)$ governs the curvature of the utility function, and has values of $0-1$. As $\alpha$ approaches 1 , the subjective utility increases in direct proportion to the outcome value; as $\alpha$ approaches 0 , the subjective utility increases in a stepwise fashion so that all gains and all losses are subjectively equal. ${ }^{22}$ The loss-aversion parameter $(\lambda)$ indicates the decision-maker's sensitivity to losses compared with gains $(0<\lambda<5)$. A value of 0 indicates no sensitivity to losses, a value of 1 reflects the same sensitivity to gains and to losses, and values $>1$ reflect more sensitivity to losses than to gains.

The recency parameter was measured by the following equation:

$$
E_{j}(t)=A \cdot E_{j}(t-1)+\delta_{j}(t) \cdot u(t) .
$$

In the earlier equation, $E_{j}(t)$ indicates the expectancy about card $j$ after selecting card $j$ on the $t^{\text {th }}$ trial, $u(t)$ indicates the subjective utility of the outcome of card selection on the $t^{\text {th }}$ trial, and $\delta_{j}(t)$ is a dummy parameter ( 1 if card $j$ is selected, 0 if card $j$ is not selected). The recency parameter $(0<A<1)$ is an index of the learning rate and shows how much weight is given to past experience with a given deck (as $A$ approaches 1) versus how much weight is placed on the value of the most recent selection from that deck (as $A$ approaches 0$)^{21}$

The following equation was used to measure the consistency parameter:

$$
\operatorname{Pr}[D(t+1)=j]=\frac{e^{\theta(t) \cdot E_{j}(t)}}{\sum_{k=1}^{4} e^{\theta(t) \cdot E_{k}(t)}} .
$$

In the earlier equation, $\operatorname{Pr}[D(t+1)=j]$ indicates the probability of selecting card $j$ on the next trial, and $\theta$ reflects the degree to which card selection is sensitive to expectancies. Therefore, values of $\theta$ that approach 0 reflect random selection, and higher values of $\theta$ reflect consistent selection based on expectancy. Because the PVL model applies a trial-independent choice rule, $\left(\theta(t)=3^{c}-1\right), \theta$ increases or decreases as trials progress. The consistency parameter $(c)$ is an indicator of the consistency between the decision-maker's selections and his or her expectancies as the trials progress.

\section{Statistical analysis}

The demographic characteristics of members of the schizophrenia and control groups were compared using one-way analysis of variance (ANOVA). Total net scores on the IGT were analyzed with univariate analysis of covariance (ANCOVA), with IQ, antipsychotic drug dosage (chlorpromazine equivalent), and sex as covariates, and block net scores were analyzed by ANCOVA, mixed design, with block as a within-subject factor, group as a between-subjects factor, and IQ, antipsychotic drug dosage (chlorpromazine equivalent), and sex as covariates. Deck selection was also analyzed with mixed design, ANCOVA treating deck as a within-subject factor, group as a between-subjects factor, and IQ, antipsychotic drug dosage (chlorpromazine equivalent), and sex as covariates. PVL parameters were estimated with the Markov chain Monte Carlo sampling scheme in OpenBugs and BRugs, its interface to $R{ }^{28}$ A total of 1,000 samples were drawn after 500 burn-in samples 
Table 3 Demographic characteristics of schizophrenia and control groups

\begin{tabular}{|c|c|c|c|c|c|c|}
\hline \multirow{2}{*}{$\begin{array}{l}\text { Demographic } \\
\text { variables }\end{array}$} & \multicolumn{2}{|c|}{ Schizophrenia $(n=39)$} & \multicolumn{2}{|c|}{ Control $(n=31)$} & \multirow[t]{2}{*}{ F-value } & \multirow[t]{2}{*}{$P$-value } \\
\hline & Mean (SD) & {$[95 \% \mathrm{Cl}]$} & Mean (SD) & {$[95 \% \mathrm{Cl}]$} & & \\
\hline Age (years) & $38.85(9.52)$ & {$[35.71,41.93]$} & $38.32(9.12)$ & {$[34.98,41.67]$} & 0.05 & 0.817 \\
\hline Education (years) & $13.03(2.12)$ & {$[12.78,13.4 \mid]$} & I3.96 (2.40) & {$[13.41,14.16]$} & 1.06 & 0.739 \\
\hline IQ & $96.44(12.51)$ & {$[92.38,100.49]$} & III.84 (10.50) & {$[107.99,115.69]$} & 30.10 & 0.000 \\
\hline \multicolumn{7}{|l|}{ PANSS } \\
\hline Positive & $19.92(4.74)$ & & & & & \\
\hline Negative & $19.92(3.44)$ & & & & & \\
\hline General pathology & $41.21(5.43)$ & & & & & \\
\hline Total & $81.05(10.57)$ & & & & & \\
\hline
\end{tabular}

Abbreviations: PANSS, the Positive and Negative Syndrome Scale; SD, standard deviation; $\mathrm{Cl}$, confidence interval.

with three chains, and the estimated parameters were analyzed with the Mann-Whitney $U$-test. Associations between schizophrenic symptoms and PVL parameters were analyzed by bootstrapped Pearson product correlation.

\section{Results}

\section{Demographic characteristics}

The schizophrenia and control groups did not differ in terms of age $(F(1,69)=0.05, P=0.817)$ or educational level $(F(1,69)=1.06, P=0.739)$. However, the two groups differed in terms of IQ $(\mathrm{F}(1,69)=30.10, P=0.000)$ as measured by the Korean version of the Wechsler Adult Intelligence Scale. ${ }^{29}$ The full-scale IQ of patients with schizophrenia was significantly lower than that of normal controls. The demographic characteristics of the two groups are presented in Table 3.

\section{Total net scores and block net scores on the IGT}

The total net scores of the two groups differed significantly $\left(F(1,65)=6.11, P=0.016, \eta_{\mathrm{p}}^{2}=0.086\right)$, with the schizophrenia group obtaining significantly lower total net scores than the control group. In terms of block net scores, we found a main effect of group $\left(F(1,65)=6.11, P=0.016, \eta_{\mathrm{p}}^{2}=0.086\right)$. The schizophrenia group obtained significantly lower block net scores than the control group. An interaction effect of group $\times$ block was also observed $\left(F(4,260)=2.55, P=0.04, \eta_{\mathrm{p}}^{2}=0.038\right)$. The block net scores of the two groups for each block and the performance of each group over the five blocks were further analyzed using univariate ANCOVA and repeatedmeasures ANOVA, respectively. To reduce type 1 errors, Bonferroni corrections were used. The block net scores of the schizophrenia and control groups did not differ in the first $\left(F(1,65)=0.13, P=0.723, \eta_{\mathrm{p}}^{2}=0.002\right)$, second $(F(1,65)=0.83$, $\left.P=0.365, \eta_{\mathrm{p}}^{2}=0.013\right)$, and third $(F(1,65)=1.43, P=0.236$, $\left.\eta_{\mathrm{p}}^{2}=0.022\right)$ blocks. However, patients with schizophrenia obtained significantly lower block net scores in the fourth $\left(F(1,65)=5.53, P=0.022, \eta_{\mathrm{p}}^{2}=0.078\right)$ and fifth $(F(1,65)=7.51$, $\left.P=0.008, \eta_{\mathrm{p}}^{2}=0.104\right)$ blocks. Additionally, the scores of the schizophrenia group did not significantly differ across the five blocks $\left(F(4,152)=0.64, P=0.634, \eta_{\mathrm{p}}^{2}=0.017\right)$, whereas those of the control group increased as the blocks progressed $\left(F(4,120)=4.71, P=0.001, \eta_{\mathrm{p}}^{2}=0.136\right)$. The mean total net and block net scores of the schizophrenia and control groups are presented in Table 4.

Table 4 The mean total net scores, block net scores, deck selections of the IGT in schizophrenia and control groups

\begin{tabular}{|c|c|c|c|c|c|c|}
\hline \multirow[t]{2}{*}{ IGT } & \multicolumn{2}{|c|}{ Schizophrenia $(n=39)$} & \multicolumn{2}{|c|}{ Control $(n=3 I)$} & \multirow[t]{2}{*}{ F-value } & \multirow[t]{2}{*}{$P$-value } \\
\hline & Mean (SD) & {$[95 \% \mathrm{Cl}]$} & Mean (SD) & {$[95 \% \mathrm{Cl}]$} & & \\
\hline Total net score & $-9.73(13.83)$ & {$[-15.00,-4.32]$} & $2.60(10.66)$ & {$[-3.70,8.91]$} & 6.11 & 0.016 \\
\hline Block I & $-2.36(4.92)$ & {$[-4.08,-0.22]$} & $-2.52(4.03)$ & {$[-5.06,-0.5 \mathrm{I}]$} & 0.13 & 0.723 \\
\hline Block 2 & $-1.44(4.59)$ & {$[-3.20,0.25]$} & $-0.06(3.24)$ & {$[-2.05,2.03]$} & 0.83 & 0.365 \\
\hline Block 3 & $-2.36(4.13)$ & {$[-3.31,0.21]$} & $1.42(4.26)$ & {$[-1.67,2.48]$} & 1.43 & 0.236 \\
\hline Block 4 & $-1.38(3.98)$ & {$[-3.58,0.12]$} & $1.87(4.73)$ & {$[0.13,4.49]$} & 5.53 & 0.022 \\
\hline Block 5 & $-1.74(4.00)$ & {$[-4.90,-0.62]$} & $1.42(6.37)$ & {$[0.17,5.22]$} & 7.51 & 0.008 \\
\hline \multicolumn{7}{|l|}{ Four decks } \\
\hline Deck A & $24.26(9.6 I)$ & {$[19.76,26.31]$} & $19.48(5.32)$ & {$[17.15,24.89]$} & 0.44 & 0.509 \\
\hline Deck B & $30.38(8.17)$ & [28.7I, 34.88] & $29.45(6.86)$ & {$[24.04,31.32]$} & 2.06 & 0.156 \\
\hline Deck C & $24.77(5.35)$ & {$[21.19,25.89]$} & $21.35(6.04)$ & {$[20.13,25.68]$} & 0.09 & 0.772 \\
\hline Deck D & $20.59(4.52)$ & {$[18.76,24.50]$} & $29.71(8.96)$ & [25.01, 31.79] & 6.45 & 0.014 \\
\hline
\end{tabular}

Abbreviations: SD, standard deviation; $\mathrm{Cl}$, confidence interval; IGT, lowa Gambling Task. 


\section{Deck selection}

A significant group $\times$ deck interaction was observed $\left(F(3,195)=2.88, P=0.05, \eta_{\mathrm{p}}^{2}=0.052\right)$; specifically, the two groups differed in the selection of deck $\mathrm{D}(F(1,65)=6.45$, $P=0.014, \eta_{\mathrm{p}}^{2}=0.09$ ), with the control group selecting cards from deck D more frequently than the schizophrenia group. No significant main effects of $\operatorname{deck}(F(3,195)=2.14, P=0.097$, $\left.\eta_{\mathrm{p}}^{2}=0.032\right)$ and group $\left(F(1,65)=0.00, P=1.000, \eta_{\mathrm{p}}^{2}=0.000\right)$ were found. The mean number of cards selected from each of the four decks is presented in Table 4 .

\section{PVL model parameters}

The control group scored significantly higher with regard to the utility-shape ( $U=23.00, P<0.001)$, loss-aversion ( $U=64.00, P<0.001)$, recency $(U=35.00, P<0.001)$, and consistency $(U=114.00, P<0.01)$ parameters than the schizophrenia group. The median values on the PVL model parameters of the schizophrenia and control groups are presented in Table 5 .

\section{Correlations between schizophrenic symptoms and PVL parameters}

There were no significant associations between schizophrenic symptoms and PVL parameters.

\section{Discussion}

This study used the IGT to investigate deficits in risk-reward related decision-making among patients with schizophrenia, and applied the PVL model to elucidate processes underlying the poor performance of patients with schizophrenia on this task. The schizophrenia and healthy control groups differed in total net scores, block net scores, and deck selection on the IGT.

The schizophrenia group had significantly lower total net scores on the IGT than the healthy control group, consistent with previous results, ${ }^{9,12}$ indicating that patients with schizophrenia selected cards from advantageous decks significantly less frequently compared to healthy controls. Patients with schizophrenia also had significantly lower scores on the fourth and fifth blocks than the healthy controls. The block net scores of the control group increased as the trials progressed, whereas no such increase in block net scores was observed in the schizophrenia group. These results are consistent with those of previous studies, ${ }^{9,10,13}$ and indicate that members of the healthy control group learned which decks were advantageous based on the outcomes of card selection, whereas this learning did not occur in patients with schizophrenia. Additionally, patients with schizophrenia selected cards from deck D significantly less frequently than the control group. These results suggest that patients with schizophrenia demonstrate deficits in decision-making.

Successful performance on the IGT requires that participants learn the contingencies of gains and losses, and learning these contingencies requires an extended period of trials because the magnitudes and frequencies of the gain and loss vary across decks. ${ }^{30}$ At the outset, healthy participants switch from one deck to another to learn the contingencies via trial and error. However, as the trials progress, participants learn the frequencies and magnitudes of gain and loss, and their preference becomes biased toward decks with higher net gains. ${ }^{31}$ Therefore, the present results showing that patients with schizophrenia obtained lower total net scores, and lower block net scores on the fourth and fifth blocks indicate that patients with schizophrenia have difficulty in learning the expected value of each deck.

In addition, patients with schizophrenia selected cards from deck D significantly less frequently than the control group. Decks A and C deliver smaller but more frequent losses, whereas decks B and D deliver larger but less frequent losses. Therefore, choice or avoidance of decks A and C can be attributed to the frequency of losses, whereas choice or avoidance of decks $\mathrm{B}$ and $\mathrm{D}$ requires a more complicated calculation of expected value considering both frequency and magnitude of losses. ${ }^{30}$ In the present study, patients with schizophrenia selected deck $\mathrm{D}$ at significantly lower rates than healthy controls, and chose decks $\mathrm{A}$ and $\mathrm{C}$ at higher rates, although the latter was not statistically significant (Table 4). In other words, patients with schizophrenia preferred decks with frequent, small losses but avoided infrequent, large losses. These results differ from those found in healthy

Table 5 The median values of PVL model parameters of schizophrenia and control groups

\begin{tabular}{lllll}
\hline PVL parameters & Schizophrenia $(\mathbf{n}=\mathbf{3 9})$ & Control $(\mathbf{n}=\mathbf{3 1}$ ) & U-value & P-value \\
\hline Utility shape & 0.07 & 0.35 & 23.00 & 0.000 \\
Loss aversion & 0.11 & 1.47 & 64.00 & 0.000 \\
Recency & 0.13 & 0.65 & 35.00 & 0.008 \\
Consistency & 0.03 & 0.71 & 114.00 & 0.002 \\
\hline
\end{tabular}

Abbreviation: PVL, Prospect Valence Learning. 
participants. For example, Steingroever et al ${ }^{32}$ investigated the performance of healthy participants on the IGT and found that healthy participants preferred decks with infrequent losses. Therefore, the present results suggest that patients with schizophrenia cannot consider the magnitude and frequency of losses simultaneously in guiding choices. ${ }^{30}$

The application of the PVL model to the data from patients with schizophrenia further revealed that poor contingency learning contributed to the poor IGT performance of this group. The schizophrenia group obtained significantly lower values for the utility-shape, loss-aversion, recency, and consistency parameters of the PVL model than the control group. The PVL model explains the learning required for the IGT as a process of forming and revising expectancies about options, and it assumes that expectancies about options are updated according to the subjective utility and outcomes of the cards selected on previous trials.

As the value of the utility-shape parameter increases, the subjective utility is updated according to actual outcomes. In the present study, the schizophrenia group had significantly lower values on the utility-shape parameter compared with the control group. This result indicates that patients with schizophrenia did not update subjective utility even though they experienced large losses by selecting cards from disadvantageous decks (A and B). Patients with schizophrenia also showed significantly lower values on the loss-aversion parameter than normal controls, and patients with schizophrenia were less sensitive to loss than to gain $(\lambda=0.11)$, whereas normal controls were more sensitive to loss than to gain $(\lambda=1.03)$. These results are consistent with those of previous studies. ${ }^{3,9,33}$ For example, Kester et $\mathrm{al}^{9}$ used the EVL model to analyze IGT performance in patients with schizophrenia, and observed that patients with schizophrenia showed a gain-biased pattern characterized by ignoring losses and preferring gains.

In the present study, the schizophrenia group had significantly lower values on the recency parameter compared with the control group. This result indicates that patients with schizophrenia do not incorporate experiences of outcomes on previous trials into expectancies about options on the subsequent trial. In other words, patients with schizophrenia either have difficulties in learning information about contingencies governing options, ${ }^{23}$ or experience rapid decay of previously learned information. ${ }^{34}$

The consistency parameter reflects the degree to which cards from advantageous decks are consistently selected, and the value of this parameter is expected to increase as trials progress. ${ }^{35}$ In the present study, the schizophrenia group had significantly lower values and showed significantly less variation in these values during task performance than the control group. These results indicate that the control group consistently selected cards from advantageous decks as the trials progressed, whereas the patient group selected cards randomly throughout the trials. These results further indicate that patients with schizophrenia could not learn which decks were advantageous or disadvantageous, and made random or impulsive choices throughout the five blocks. ${ }^{34}$

Previous studies have reported that patients with schizophrenia and healthy controls differ only on values of attention-to-winning, ${ }^{9}$ recency, ${ }^{15}$ or recency and consistency parameters $^{23}$ of the EVL model. However, in the present study, patients with schizophrenia exhibited significantly lower values for all four parameters of the PVL model than healthy controls. These inconsistent findings may be related to methodological differences, particularly participant characteristics such as age, duration of illness, or the ratio of male to female participants. For example, Kester et al ${ }^{9}$ investigated decision-making impairments in adolescents with early-onset schizophrenia with participants much younger than those in the current study. Aging is known to affect IGT performance, ${ }^{36}$ and chronic patients exhibit poorer performance on various neuropsychological tests of executive function ${ }^{37}$ and memory, ${ }^{38}$ both of which are significantly associated with performance on the IGT.,39 Therefore, the low values among the schizophrenia group on all four parameters of the PVL model in this study may be at least partially explained by the fact that the sample consisted of chronic patients rather than the first-episode patients studied by Kester et al. In addition, Premkumar et $\mathrm{a}^{15}$ employed almost three times more male than female participants, whereas in the current study, the ratio of male to female participants was approximately $1: 1.2$. Sex differences on IGT performance have been reported, with males generally outperforming females. ${ }^{4,40}$

Our study had several limitations that should be addressed in future studies. First, the inclusion of a small number of participants limits the generalizability of these findings. Second, even though we applied the PVL model to enhance understanding of the mechanisms contributing to poor IGT performance in patients with schizophrenia, the PVL model is based on behavioral data from the IGT. Therefore, future studies should employ neuroimaging techniques to enhance our understanding of the poor performance of patients with schizophrenia on the IGT. Third, since previous studies have reported that performance on the IGT is significantly associated with performance on neuropsychological tests 
evaluating working memory and executive function, future studies that administer both the IGT and neuropsychological tests should provide information about the relationship between IGT performance and neuropsychological functions. Finally, performance on the IGT reflects the ability to use emotional signals in guiding decision-making. Past studies have found that patients with damage to the ventromedial region of the prefrontal cortex, which interferes with processing of emotional signals, prefer the disadvantageous decks more often than normal controls ${ }^{41,42}$ and that patients with schizophrenia have deficits in emotional processing. ${ }^{43}$ Therefore, future research investigating both decision-making and emotional processing in patients with schizophrenia should provide valuable information regarding the role of emotional processing on IGT performances.

In conclusion, patients with schizophrenia had significantly lower total net scores and block net scores in the fourth and fifth blocks, and they selected cards from deck D less frequently than healthy controls. The control group obtained increased block net scores as the trials progressed, whereas the scores of the schizophrenia group did not significantly differ across blocks. Application of the PVL model showed that the schizophrenia group had significantly lower values on the utility-shape, loss-aversion, recency, and consistency parameters. These results suggest that patients with schizophrenia have deficits in decision-making, possibly due to failures in contingency learning that are required to distinguish between advantageous and disadvantageous decks when integrating the frequencies and magnitudes of loss and gain so as to predict the outcome of card choices, and in incorporating experiences of outcomes on previous trials into expectancies about options on the present trial.

\section{Acknowledgment}

This work was supported by the National Research Foundation of Korea Grant funded by the Korean government (NRF-2013S1A5A2A01018533).

\section{Disclosure}

The authors report no conflicts of interest in this work.

\section{References}

1. Cattapan-Ludewig K, Ludewig S, Messerli N, et al. Decision-making dysregulation in first-episode schizophrenia. J Nerv Men Dis. 2008; 196(2):157-160.

2. Ernst M, Paulus MP. Neurobiology of decision making: a selective review from a neurocognitive and clinical perspective. Biol Psychiatry. 2005;58(8):597-604.

3. Heerey EA, Bell-Warren KR, Gold JM. Decision-making impairments in the context of intact reward sensitivity in schizophrenia. Bio Psychiatry. 2008;64(1):62-69.
4. Bechara A, Damasio AR, Damasio H, Anderson SW. Insensitivity future consequences following damage to human prefrontal cortex. Cognition. 1994;50(1-3):7-15.

5. Bechara A, Damasio H, Damasio AR. Emotion, decision making and the orbitofrontal cortex. Cereb Cortex. 2000;10(3):295-307.

6. Clark L, Robbins TW. Decision-making. In: Wood SJ, Allen NB, Pantelia C, editors. The neuropsychology of mental illness. Cambridge: Cambridge University Press; 2009:138-156.

7. Bechara A. Iowa gambling task professional manual. Lutz: FL: Psychological Assessment Resources; 2007.

8. Brand M, Grabenhorst F, Starcke K, Vandekerckhove MM, Markowitsch HJ. Role of the amygdala in decision under ambiguity and decisions under risk: evidence from patients with Urbach-Wiethe disease. Neuropsychologia. 2007;45(6):1305-1317.

9. Kester HM, Sevy S, Yechiam E, Burdick KE, Cervellion KL, Kumra S. Decision-making impairments in adolescent with early-onset schizophrenia. Schizophr Res. 2006;85(1-3):113-123.

10. Shurman B, Horan WP, Nuechterlein KH. Schizophrenia patients demonstrate a distinctive pattern of decision-making impairment on the Iowa Gambling Task. Schizophr Res. 2005;72(2-3):215-224.

11. Struglia F, Stratta P, Gianfelice D, Pacifico R, Riccardi I, Rossi A. Decision-making impairment in schizophrenia: relationships with positive symptomatology. Neurosci Lett. 2011;502(2):80-83.

12. Ritter LM, Meador-Woodruff JH, Dalack GW. Neurocognitive measures of prefrontal cortical dysfunction in schizophrenia. Schizophr Res. 2004;68(1):65-73.

13. Lee Y, Kim YT, Seo E, et al. Dissociation of emotional decision-making from cognitive decision-making in chronic schizophrenia. Psychiatry Res. 2007;152(2-3):113-120.

14. Nestor PG, Choate V, Niznikiewicz M, Levitt JJ, Shenton ME, McCarley RW. Neuropsychology of reward learning and negative symptoms in schizophrenia. Schizophr Res. 2014;159(2-3):506-508.

15. Premkumar P, Fannon D, Kuipers E, Simmons A, Frangou S, Kumari V. Emotional decision-making and its dissociable components in schizophrenia and schizoaffective disorder: a behavioural and MRI investigation. Neuropsychologia. 2008;46(7):2002-2012.

16. Evans $\mathrm{CE}$, Bowman $\mathrm{CH}$, Tumbull $\mathrm{OH}$. Subjective awareness on the Iowa Gambling Task: the key role of emotional experience in schizophrenia. J Clin Exp Neuropsychol. 2005;27(6):656-664.

17. Rodriguez-Sanchez JM, Crespo-Facorro B, Perez-Iglesias R, et al. Prefrontal cognitive functions in stabilized first-episode patients with schizophrenia spectrum disorders: a dissociation between dorsolateral and orbitofrontal functioning. Schizophr Res. 2005;77(2-3):279-288.

18. Beninger RJ, Wasserman J, Zanibbi K, Charbonneau D, Mangels J, Beninger BV. Typical and atypical antipsychotic medications differentially affect two nondeclarative memory tasks in schizophrenic patients: a double dissociation. Schizophr Res. 2003;61(2-3):281-292.

19. Busemeyer JR, Stout JC. A contribution of cognitive decision models to clinical assessment: decomposing performance on the Bechara gambling task. Psychol Assess. 2002;14(3):253-262.

20. Yechiam E, Busemeyer JR, Stout JC, Bechara A. Using cognitive models to map relations between neuropsychological disorders and human decision-making deficits. Psychol Sci. 2005;16(12):973-978.

21. Ahn WY, Busemeyer JR, Wagenmakers EJ, Stout JC. Comparison of decision learning models using the generalization criterion method. Cogn Sci. 2008;32(8):1376-1402.

22. Fridberg DJ, Queller S, Ahn WY, et al. Cognitive mechanisms underlying risky decision-making in chronic cannabis users. J Math Psychol. 2010;54(1):28-38.

23. Brambilla P, Perlini C, Bellani M, et al. Increased salience of gains versus decreased associative learning differentiate bipolar disorder from schizophrenia during incentive decision making. Psychol Med. 2013;43(3):571-580.

24. American Psychiatric Association. Diagnostic and Statistical Manual of Mental Disorders, 4th ed. Washington DC: American Psychiatric Association Press; 1994:285-286. 
25. Kay SR, Fizbein A, Opler LA. The Positive and Negative Syndrome Scale (PANSS) for schizophrenia. Schizophr Bull. 1987;13(2): 261-276.

26. Gardner DM, Murphy AL, O’Donnell H, Centorrino F, Baldessarini RJ. International consensus study of antipsychotic dosing. Am J Psychiatry. 2010;167(6):686-693.

27. First MB, Spitzer RL, Gibbson M, Williams JB. Structured clinical interview for DSM-IV Axis I disorder, research version, non-patient edition (SCID-I-NP). New York: New York State Psychiatric Institute; 1996.

28. R Development Core Team. R: a language and environment for statistical computing. Vienna: R Foundation for Statistical Computing; 2009.

29. Yum TH, Park YS, Oh KJ, Kim JG, Lee YH. Manual of the KoreanWechsler Adult Intelligence Scale. Seoul: Korean Guidance Press; 1992.

30. Brown EC, Hack SM, Gold JM, et al. Integrating frequency and magnitude information in decision-making in schizophrenia: an account of patient performance on the Iowa gambling task. J Psychiatr Res. 2015;66-67:16-23.

31. Bull PN, Tippett LJ, Addis DR. Decision making in healthy participants on the Iowa Gambling Task: insight from an operant approach. Front Psychol. 2015;6:391.

32. Steingroever H, Wetzels R, Horstmann A, Neumann J, Wagenmakers EJ. Performances of healthy participants on the Iowa Gambling Task. Psychol Assess. 2013;25(1):180-193.

33. Tremeau F, Brady M, Saccente E, et al. Loss aversion in schizophrenia. Schizophr Res. 2008;103(1-3):121-128.

34. Vassileva J, Ahn WY, Weber KM, et al. Computational modeling reveals distinct effects of HIV and history of drug use on decision making processes in women. PLoS One. 2013;8(8):e68962.

35. Sandra W. Challenging the somatic marker hypothesis [MS dissertation]. Vienna, Austria: Universitat Wien; 2009.
36. Carvalho JC, Cardoso Cde O, Shneider-Bakos D, Kristensen CH, Fonseca RP. The effect of age on decision making according to the Iowa gambling task. Span J Psychol. 2012;15(2):480-486.

37. Premkumar P, Kumari V, Corr PJ, Fannon D, Sharma T. Neuropsychological function-brain structure relationships and stages of illness: an investigation into chronic and first-episode schizophrenia. Psychiatry Res. 2008;162(3):195-204.

38. Ohrmann P, Siegmund A, Suslow T, et al. Cognitive impairment and in vivo metabolites in first-episode neuroleptic-naïve and chronic medicated schizophrenia patients: a proton magnetic resonance spectroscopy study. J Psychiatr Res. 2007;41(8):625-634.

39. Yip SW, Sacco KA, George TP, Potenza MN. Risk/reward decisionmaking in schizophrenia: a preliminary examination of the influence of tobacco smoking and relationship to Wisconsin card sorting task performance. Schizophr Res. 2009;110(1-3):156-164.

40. Reavis R, Overman WH. Adult sex differences on a decision-making task previously shown to depend on the orbital prefrontal cortex. Behav Neurosci. 2001;115(1):196-206.

41. Bechara A. The role of emotion in decision-making: evidence from neurological patients with orbitofrontal damage. Brain Cogn. 2004; 55(1):30-40.

42. Waters-Wood SM, Xiao L, Denburg NL, Hernandez M, Bechara A Failure to learn from repeated mistakes: persistent decision-making impairment as measured by the Iowa gambling task in patients with ventromedial prefrontal cortex lesion. J Int Neuropsychol Soc. 2012; 18(5):927-930.

43. Silver H, Bilker W, Goodman C. Impaired recognition of happy, sad, and neutral expressions in schizophrenia is emotion, but not valence, specific and context dependent. Psychiatry Res. 2009;169(2):101-106.
Neuropsychiatric Disease and Treatment

\section{Publish your work in this journal}

Neuropsychiatric Disease and Treatment is an international, peerreviewed journal of clinical therapeutics and pharmacology focusing on concise rapid reporting of clinical or pre-clinical studies on a range of neuropsychiatric and neurological disorders. This journal is indexed on PubMed Central, the 'PsycINFO' database and CAS,

\section{Dovepress}

and is the official journal of The International Neuropsychiatric Association (INA). The manuscript management system is completely online and includes a very quick and fair peer-review system, which is all easy to use. Visit http://www.dovepress.com/testimonials.php to read real quotes from published authors. 